\title{
Stimulus suffix effects in recognition memory
}

\author{
ROBERT L. GREENE \\ Case Western Reserve University, Cleveland, Ohio
}

\begin{abstract}
Recall of auditory items can be disrupted by presentation of an irrelevant auditory stimulus (a stimulus suffix). Previous researchers have suggested that suffix effects are not found on recognition tests. Two experiments are presented here that demonstrate suffix effects on recognition tests. These results suggest that suffixes interfere with item information and that suffix effects cannot be attributed solely to retrieval processes.
\end{abstract}

Recall of a list of auditory items is disrupted if an irrelevant auditory stimulus (a stimulus suffix) is presented after the last item. Suffix effects may extend throughout the list, but tend to be greatest by far on the last one or two items (e.g., Crowder, 1967; Dallett, 1965; Morton, Crowder, \& Prussin, 1971).

For many years, suffix effects were interpreted as resulting from interference in auditory sensory (echoic) memory (Crowder \& Morton, 1969; O. C. Watkins \& M. J. Watkins, 1980). However, a number of findings reported in recent years seem inconsistent with this approach (e.g., Greene \& Crowder, 1984; Nairne \& Crowder, 1982; Nairne \& Walters, 1983; Shand \& Klima, 1981; Spoehr \& Corin, 1978). As a result, there have been both attempts to revise the echoic-memory account to reconcile it with recent findings (Crowder, 1983; Greene \& Crowder, 1984, 1986; Greene \& Samuel, 1986) and attempts to construct entirely new theories of suffix effects (e.g., Broadbent \& Broadbent, 1981; Campbell \& Dodd, 1980; Penney, 1985; Spoehr \& Corin, 1978; Shand \& Klima, 1981).

The echoic-memory theory of suffix effects, as well as at least some of the alternative accounts, assumes that suffixes cause a loss of item information in memory. This assumption was challenged by Parkinson (1978), who claimed that suffixes affect order information in memory, but not item information; in other words, he suggested that suffixes do not interfere with memory for what items occurred on a list, but only with memory for the order of the items. Parkinson supported this claim by reporting a study in which he found no suffix effects on a recognition test. Cowan and Kielbasa (1986) reported similar findings. Since recognition tests require item information but not order information, a null effect of suffixes in recognition is consistent with the claim that suffixes do not interfere with item information.

Before engaging in too much theoretical speculation, one should make sure that the conclusion that suffix effects are not found in recognition is well founded. Questions can be raised about the adequacy of the previous studies. Par-

\footnotetext{
Correspondence concerning this article should be addressed to Robert L. Greene, Department of Psychology, Case Western Reserve University, Cleveland, $\mathrm{OH} 44106$.
}

kinson's (1978) data suffered from a ceiling effect: Performance at the end of the list was almost $100 \%$ in both the suffix and control (no-suffix) conditions, so interpretation of the null result was impossible. Parkinson tried to handle this problem by reporting separately data from the 6 subjects with the lowest overall recognition scores. However, even these subjects were near ceiling at the end of the list for both conditions, so this analysis is irrelevant.

Cowan and Kielbasa's (1986) results are also difficult to interpret. They used a task very different from standard suffix experiments or recognition tests. Subjects received short (two- or four-item) lists of nonsense syllables. Lists were followed either by a speech suffix or by a tongue cluck (which was intended to be ineffective as a suffix and therefore appropriate to a control condition). At time of test, subjects were shown pictures and were told to decide which pictures depicted objects whose names rhymed with a list item. It is not clear whether one can generalize from this sort of rhyming task with short lists to more common suffix-effect experiments or recognition procedures. In addition, there is no evidence that the tongue cluck itself was not an effective suffix, which would certainly make it inappropriate for use as a control. Moreover, the results were very complex. A significant main effect of suffix type was found in children but not in adults. The suffix did interact with other variables in the adult sample, suggesting that differential suffix effects were present in some conditions but not in others. Given the complexity of both the procedure and the results, it is not clear what conclusions can be drawn from this study.

The present experiments were intended to resolve the question of whether suffix effects are found in recognition. They were designed to avoid ceiling effects. The experiments were also designed to differ greatly from each other. Suffix effects are found in a variety of conditions in recall, and in these experiments an attempt was made to duplicate several of these conditions.

\section{EXPERIMENT 1}

In Experiment 1, immediate recognition of lists of eight auditory letters was studied. Lists were followed either by a suffix or by silence. 


\section{Method}

Subjects. Twenty-four students from introductory psychology classes at Case Western Reserve University participated to fulfill a course requirement. The subjects were tested in groups of 6 .

Materials. Letters were used as to-be-remembered items. In all, 66 lists, each composed of a random sequence of eight letters, were constructed. The only constraint in assigning letters to lists was that each letter occur only once on a list. The lists were read in a male experimenter's voice at a rate of one item per second and recorded on cassette tape. Half of the lists were followed by a suffix (the word BEGIN in the same voice and on the same tape as the items), and the other lists were followed only by silence. Suffix and nosuffix lists were randomly interspersed. To prevent intonation differences between suffix and no-suffix lists, the lists were recorded as the experimenter read them from a computer display screen that showed items one at a time. The experimenter did not know which lists contained suffixes until after the last item had been shown to him.

Procedure. At the beginning of the experiment, the subjects were given a stack of 66 cards face down. After each list was played on tape, the subjects turned over one of the cards. Each card contained 16 letters printed in alphabetical order, 8 letters that had been on the preceding list and 8 randomly chosen distractors. The subjects were to circle letters that had been on the list and cross out letters that had not been on the list. The subjects were told to begin at the left end of the sequence and make their way rightward without skipping test stimuli and without backtracking. They were urged to avoid making false-positive errors. There were $20 \mathrm{sec}$ allotted between lists for this test.

The first six lists were considered practice and were not scored.

\section{Results}

All significance tests reported here were performed on the number of items recognized, and a .05 significance level was used.

The mean proportions of items correctly recognized are shown in Figure 1. The false-alarm rate (that is, the proportion of distractors that were circled) was .06 for both suffix and no-suffix lists. The data resembled the typical findings from recall experiments, with the suffix having its greatest effect at the end of the list. An analysis of variance found significant effects of the suffix $[F(1,23)=9.28, M S \mathrm{e}=5.27]$ and serial position $[F(7,161)=11.40, M S e=15.17]$. The interaction between suffix and position was also significant $[F(7,161)$ $=5.70, M S e=4.23]$. When individual positions were analyzed, the suffix effect was significant only at the eighth position $[F(1,23)=39.08, M S e=4.04]$.

The immediate-recognition task used in Experiment 1 was intended to be analogous to the immediate-recall task often used to study suffix effects. Just as a subject has to recall numerous items before reaching the end of the list in immediate recall, a subject in Experiment 1 would usually make several recognition decisions before being tested on the last item. In Experiment 2, a different procedure, a delayed-recognition test, was used.

\section{EXPERIMENT 2}

Experiment 2 was designed to extend the results found in Experiment 1 in several ways. Whereas the items used in Experiment 1 all came from a restricted set (letters of

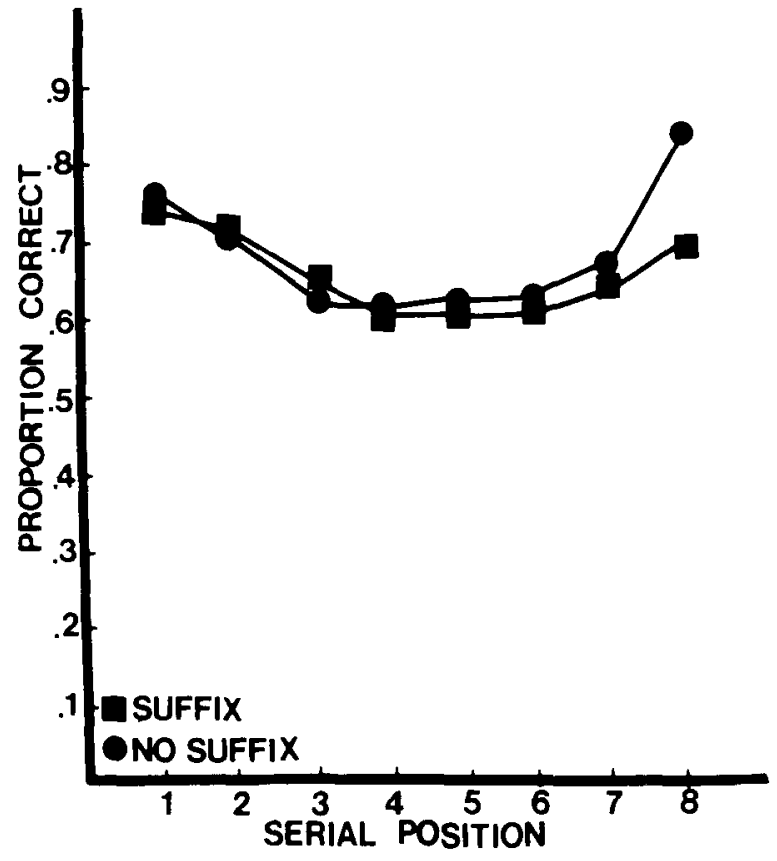

Figure 1. The proportion of items correctly recognized in Experiment 1 as a function of serial position and condition.

the alphabet), the items used in Experiment 2 were words, with no word occurring more than once in the experiment. All eight list items were tested in Experiment 1, but only one item per list was tested in Experiment 2. In Experiment 1 , the items and suffixes were presented auditorily; in Experiment 2, all list items and suffixes were presented visually, and the subjects read them aloud. The suffix and no-suffix conditions were interspersed randomly in Experiment 1, but were presented in blocked fashion in Experiment 2. Also, in Experiment 2, recognition was delayed by a $10-\sec$ filled retention interval.

\section{Method}

Subjects. Twenty-four students from introductory psychology classes at Case Western Reserve University participated to fulfill a course requirement. The subjects were tested individually.

Materials. In this experiment, 200 lists were used as stimuli, with each list composed of eight one-syllable nouns. The items were assigned randomly to serial positions, with each subject getting a different ordering of words. The word END appeared after the last item on all lists. The lists and test stimuli were presented on a display screen of an Apple Ile computer system.

Procedure. The subjects were seated in front of the display screen. Items were presented one at a time at a rate of two items per second. The subjects were required to read each item aloud as it was shown. The word END always occurred after the last item, in the same rhythm as the list.

After the word END was shown, the subjects had to perform a distractor task. Two-addend addition equations of the form $1+2=3$ were shown. The addends (that is, the numbers being added) were always between 1 and 9 . Half of the equations were true, with the other equations showing a sum that was too large or too small by 2 . The subjects were to press one key if the equation was true and a different key if it was false. Each equation was shown for $2 \mathrm{sec}$, and the subjects saw five equations after each list. In other words, there was a silent $10-\mathrm{sec}$ filled retention interval after each list. 
When this interval was complete, a word was shown, and the subjects were to press one key if it had been on the list and a different key if it had not been on the list. On $\mathbf{4 0}$ lists, this test stimulus was a distractor; on the remaining lists, it had been shown on the list. On positive trials, the computer randomly determined which of the eight items was tested, with the requirement that each position be tested 10 times in each condition. As in Experiment 1, the subjects were urged to avoid making false-positive errors.

There were two blocks of 100 trials each. In one block, the word END was read aloud by the subjects; similar procedures have been shown to cause suffix effects in recall (e.g., Crowder, 1970; Greene \& Crowder, 1984). In the other block, the subjects read the word END silently; visually presented stimuli that are read silently cause little or no interference and can be used in a control condition (Greene, 1987; Morton \& Holloway, 1970). The order of blocks was counterbalanced across subjects.

\section{Results}

The results are shown in Figure 2. The proportions of arithmetic problems correctly answered were .83 and .82 in the suffix and control conditions, respectively. The false-alarm rate in word recognition was .04 in both conditions. As was the case in Experiment 1, the suffix impaired recognition for the last item. The main effect of the suffix was not significant here $[F(1,23)=0.12, M S e$ $=2.74]$. However, there was a significant effect of serial position $[F(7,161)=16.57, M S e=3.34]$, and a significant interaction between the suffix and position $[F(7,161)$ $=2.34, M S e=1.89]$. When positions were tested individually, the suffix significantly impaired recognition only at the eighth position $[F(1,23)=17.97, M S e=$ 1.34].

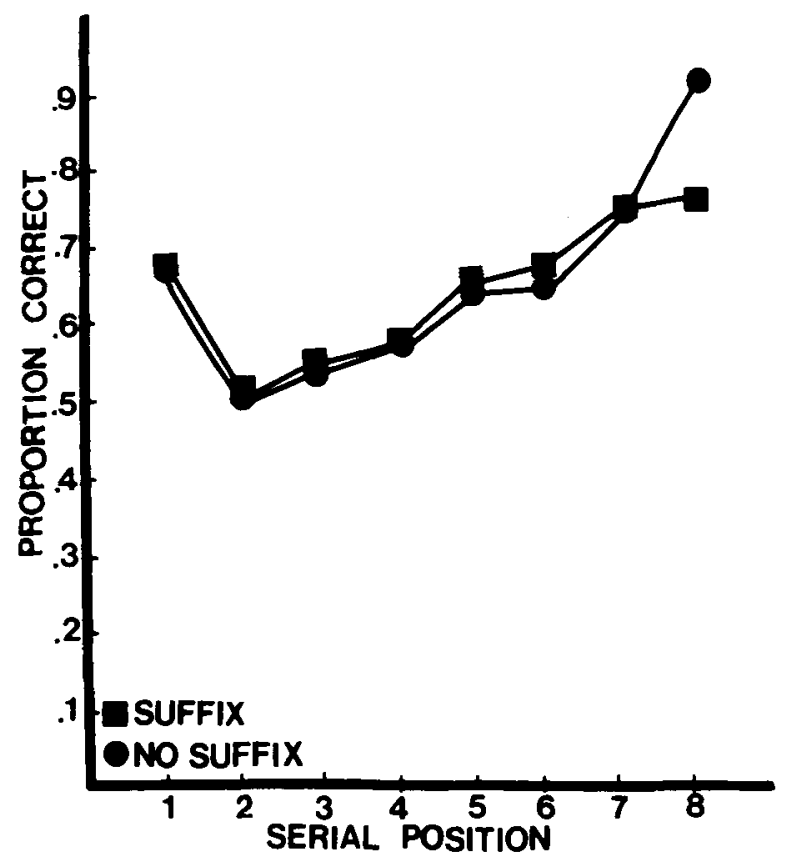

Figure 2. The proportion of items correctly recognized in Experiment 2 as a function of serial position and condition.

\section{GENERAL DISCUSSION}

The results of Experiments 1 and 2 show stimulus suffix effects in recognition. An attempt was made to capture partially the variety of situations in which suffix effects may be seen in recall. On the basis of the two experiments reported here, there is no reason to believe that any of the following factors is crucial: the source of auditory stimulation (an experimenter or the subject), the size of the stimulus set, the presence or absence of delay, or the exact testing procedure. The suffix effect in recall is also robust against manipulations of these factors.

The suffix effects found here seem clearly restricted to the last item. In recall, the suffix effect may extend farther into the list. There is evidence that the preterminal suffix effect and the terminal suffix effect may result from different processes (Baddeley \& Hull, 1979; Balota \& Engle, 1981; Greenberg \& Engle, 1983; Penney, 1985), with the preterminal suffix effect typically attributed to strategic factors, whereas the terminal suffix effect is attributed to structural memory processes. It seems possible that the strategies that underlie preterminal suffix effects in recall may not be used in recognition.

Parkinson (1978) found no suffix effect in recognition, and used this null finding to argue that suffixes affect order information but not item information. As noted previously, interpretation of Parkinson's data is complicated by ceiling effects, and the results found here suggest that suffixes do affect item information. There is also other evidence that suffixes may affect memory for items. Suffix effects are found in free recall (e.g., Engle, 1974; Roediger \& Crowder, 1976), where order information is not explicitly tested. Also, suffix effects are found in serial recall of words, even when recall is scored simply on an item criterion without regard to position (Roediger \& Crowder, 1976; M. J. Watkins \& Todres, 1979). In short, suffixes affect performance on tests that require only item information.

The results reported here do not indicate how suffixes interfere with item information. However, they may cast doubt on several possible accounts. For example, Glenberg and his collaborators (Glenberg, 1984; Glenberg, Eberhardt, \& Petersen, 1985; Glenberg \& Swanson, 1986; Huang \& Glenberg, 1986) have argued that terminal items on auditory lists are recalled through the use of temporal or contextual retrieval cues. Suffixes interfere with recall by overloading these cues; the suffix becomes associated with these cues, making them less effective in guiding retrieval of list items. However, it has been assumed that such cues are not used in recognition (Glenberg \& Kraus, 1981). If suffixes affect memory only by overloading retrieval cues, and if these cues are not used in recognition, then one would not expect to find suffix effects in recognition. Since the experiments reported here demonstrate such effects, one can conclude that this theory is not a sufficient account of suffix ef- 
fects. More generally, any theory that assumes that suffix effects result from interference in retrieval processes that are specific to recall seems inadequate.

Of course, there are many other theories that are consistent with the results found here. Echoic-memory accounts, such as those of Crowder and Morton (1969) and O. C. Watkins and M. J. Watkins (1980), predict that suffix effects would be found in recognition. There are also other theories of suffix effects in recall that could be extended to recognition (e.g., Broadbent \& Broadbent, 1981; Campbell \& Dodd, 1980; Penney, 1985; Shand \& Klima, 1981). Additional research will be needed to determine which of these proposals is most adequate. However, the present results suggest that a complete theory of suffix effects must be applicable to recognition as well as to recall.

\section{REFERENCES}

Baddeley, A., \&ull, A. (1979). Prefix and suffix effects: Do they have a common basis? Journal of Verbal Learning \& Verbal Behavior, 18, $129-140$.

Balota, D. A., \& ENGLE, R. W. (1981). Structural and strategic factors in the stimulus suffix effect. Journal of Verbal Learning \& Verbal Behavior, 20, 346-357.

Broadbent, D. E., \& Broadbent, M. H. P. (1981). Recency effects in visual memory. Quarterly Joumal of Experimental Psychology, 33A, $1-15$.

CAmpbell, R., \& DodD, B. (1980). Hearing by eye. Quarterly Journal of Experimental Psychology, 35A, 571-587.

Cowan, N., KIElbasa, L. (1986). Temporal properties of memory for speech in preschool children. Memory \& Cognition, 14, 382-390.

Crowder, R. G. (1967). Prefix effects in immediate memory. Canadian Journal of Psychology, 21, 450-461.

Crowder, R. G. (1970). The role of one's own voice in immediate memory. Cognitive Psychology, 1, 157-178.

Crowder, R. G. (1983). The purity of auditory memory. Philosophical Transactions of the Royal Society, B, 302, 251-265.

Crowder, R. G., \& Morton, J. (1969). Precategorical acoustic storage (PAS). Perception \& Psychophysics, 5, 365-373.

Dallett, K. M. (1965). "Primary memory": The effects of redundancy upon digit repetition. Psychonomic Science, 3, 237-238.

ENGLE, R. W. (1974). The modality effect: Is precategorical acoustic storage responsible? Journal of Experimental Psychology, 102, 824-829.

GLENBERG, A. M. (1984). A retrieval account of the long-term modality effect. Journal of Experimental Psychology: Learning, Memory, \& Cognition, 9, 231-255.

Glenberg, A. M., Eberhardt, K. A., * Petersen, G. L. (1985). Differential influence of the recall and postlist instruction modalities on the long-term modality effect. American Journal of Psychology, 98, 569-578.
Glenberg, A. M., Kraus, T. A. (1981). Long-term recency is not found on a recognition test. Journal of Experimental Psychology: Human Learning \& Memory, 7, 475-479.

Glenberg, A. M., \& Swanson, N. (1986). A temporal distinctiveness theory of recency and modality effects. Journal of Experimental Psychology: Leaming, Memory, \& Cognition, 12, 1-13.

GREENBERG, S. N., ENGLE, R. W. (1983). Voice change in the stimulus suffix effect: Are the effects structural or strategic? Memory \& Cognition, 11, 551-556.

GreENE, R. L. (1987). Stimulus suffixes and visual presentation. Memory \& Cognition, 15, 497-503.

Greene, R. L., \& Crowder, R. G. (1984). Modality and suffix effects in the absence of auditory stimulation. Joumal of Verbal Leaming \& Verbal Behavior, 23, 371-382.

Greene, R. L., \& Crowder, R. G. (1986). Recency effects in delayed recall of mouthed stimuli. Memory \& Cognition, 14, 355-360.

Greene, R. L., \& Samuel, A. G. (1986). Recency and suffix effects in serial recall of musical stimuli. Journal of Experimental Psychology: Learning, Memory, \& Cognition, 12, 517-524.

HUANG, S., \& Glenberg, A. M. (1986). Echoic and retrieval accounts of the long-term modality effect tested using the suffix procedure. American Journal of Psychology, 99, 453-470.

Morton, J., Crowder, R. G., \& Prussin, H. A. (1971). Experiments with the stimulus suffix effect. Journal of Experimental Psychology, 91, 169-190.

Morton, J., \& Holloway, C. M. (1970). Absence of a cross-modal suffix effect in short-term memory. Quarterly Joumal of Experimental Psychology, 22, 167-176.

Nairne, J. S., \& Crowder, R. G. (1982). On the locus of the stimulus suffix effect. Memory \& Cognition, 10, 350-357.

NAIRNE, J. S., \& WALTERS, V. L. (1983). Silent mouthing produces modality- and suffix-like effects. Journal of Verbal Learning \& Verbal Behavior, 22, 475-483.

Parkinson, S. R. (1978). An alternative interpretation of the stimulus suffix effect. Journal of Experimental Psychology: Human Learning \& Memory, 4, 362-369.

PenNey, C. G. (1985). Elimination of the suffix effect on preterminal list items with unpredictable list length: Evidence for a dual model of suffix effects. Journal of Experimental Psychology: Learning, Memory, \& Cognition, 11, 229-247.

RoEDIGER, H. L., III, \& CROWDER, R. G. (1976). Recall instructions and the suffix effect. American Journal of Psychology, 89, 115-125.

Shand, M. A., \& KLIMA, E. S. (1981). Nonauditory suffix effects in congenitally deaf signers of American Sign Language. Journal of Experimental Psychology: Human Learning \& Memory, 7, 464-474.

SPOEHR, K. T., CORIN, W. J. (1978). The stimulus suffix effect as a memory coding phenomenon. Memory \& Cognition, 6, 583-589.

W ATKINS, M. J., \& Todres, A. K. (1979). Stimulus suffix effect and the item-position distinction. Joumal of Experimental Psychology: Human Learning \& Memory, 5, 322-325.

WatkINS, O. C., \& WatkINs, M. J. (1980). The modality effect and echoic persistence. Joumal of Experimental Psychology: General, 109, 251-278.

(Manuscript received June 15, 1987; revision accepted for publication October 8, 1987.) 